\title{
THE SIMULATION OF HYSTERIA.
}

By TOM A. WILliamS, M. B., C. M. (Edin.),

Neurologist to Epiphany Free Dispensary, Washington, D. C.; Memb. Corresp. Etrang. Soc. de Neurol. de Paris; Memb. Corresp. Etrang. Soc. de Psychol. de Paris; Memb. Assoc. Soc. Med. Ment. Clin. de Paris.

Tardieu well said, "It is only by profound knowledge of the reality that it is possible to recognize its simulation." The following case is presented in illustration of this thesis. Furthermore, although a great many ruses have been used to unmask a simulator by spying and by methods often called "the third degree," the best procedures of all are those which depend upon the doctor's knowledge of the signs and evolution of disease.

This statement is particularly true with regard to hysteria; for that psychosis is one of such apparent variability that, if the concept of the doctor is vague, there is little chance of reaching precision in the diagnosis.

Unfortunately the concept of hysteria still possessed by most medical men is far from precise. ${ }^{2}$ The study of cases by a rigorous neurological technique has not received in this country the attention it merits, and which it has received more particularly in France, and more especially since Babinski ${ }^{2}$ first made a breach in the beliefs which had ruled in the days of Charcot. His keen powers of observation and skilful neurological technique had discovered the artificiality of much of the hysteria in the Salpetrière; and the kind of analysis of symptoms which he has inspired has now removed from the domain of hysteria very many conditions which were formerly included within it." Such were restriction of the visual fields and dyschromatopsia; abnormalities of the skin and tendon reflexes; vasomotor and trophic disturbances, such as œdema and skin eruptions; pupillary irregularities and inequalities. Nor is the temperature modified hysterogenically; and the urinary, sudoral and salivary secretions are not altered per se by the psychic state which we call hysteria. 
However, hysteria is sometimes manifested in consequence of a physical alteration which affects the neurones. In that case, the same physical alteration may be productive of functional perturbations of the lower neurones too, and there may accompany the hysteria exaggerated reflexes, trophic perturbations, and circulatory irregularities. Furthermore, the physical malady in question may manifest itself by fever and its accompaniments of perturbed secretion. But these themselves are not hysterical; for hysteria may, can and does occur without any physical disturbances whatever.

Hysteria then is merely a mode of reaction of the nervous system. It is purely mental, psychic; and it is determined by purely psychic causes. Even when it occurs in consequence of physically disturbed neurones, it is the psychic stimulus which arouses the particular symptom which we call hysterical in that case. The organic disease merely increases the susceptibility to react in the way we call hysterical.

But there are a great many ways of mental or psychic reaction; and hysteria is only one of these. How then shall we define and characterize that one? As I have discussed this question at great length elsewhere," I shall not do so further here, but simply adopt the conclusion which declares that by a hysterical symptom we mean "one which is susceptible of production by suggestion and of removal also by suggestion." "

Against the adoption of this definition, much has been urged, especially by alienists, who have confused with simple hysteria the compound clinical pictures, which are so common, where hysterical symptoms are only part of another psychosis. The analysis of mental symptoms is much more complex that that of neurological signs; and unfortunately no clear and honest discussion of this matter has yet occurred, such as so much clarified neurological hysteria in Paris in 1907. I fear that the time is hardly ripe for such discussion; for few alienists are capable of viewing the problem; as they are unfortunate in not seeing cases at their inception and during their evolution, at which time can best be appreciated the pathogenesis, before it becomes masked by the complications of commitment and asylum life. Besides, the alienists' interests are turned towards determination of mental un- 
soundness: questions of psychopathology are studied only by the few.

To the practitioner and neurologist in the past, the chief pitfall has been the tendency to confound with hysteria all psychoneurotic conditions. Recent work, however, has given us criteria of ready clinical applicability, and these are laid down elsewhere.'

Another common fallacy is to call emotionalism hysteria: they are really very different. Emotion is as a rule evanescent when determined psychically, and is always so unless maintained ideationally. This question has also been recently considered at the Paris neurological society in conjunction with the society of psychiatry; and also by the writer from a different aspect, before the Southern Society of Psychology.'

In relation to malingering, some recent authorities believe that the hysterical attitude, whether induced or autogenetic, is in reality a simulation, although an unconscious one. ${ }^{10}$ The question is too complex for discussion here, as the psychological ramifications to which it leads do not seem to the writer capable of solution at present. Moreover, "restriction of the field of consciousness" $"$ is a normal accompaniment of every effective concentration of mind ; and indeed the acquirement of this power is one of the objects of education. "The suppressed complex" ${ }^{2}$ is a phenomenon which few escape; but in only a few does it produce hysteria or other psychosis. Its rôle is still sub judice. At all events, its catharsis ${ }^{13}$ is not recognized as an essential therapeutic arm, and indeed many of us believe that other means are not only simpler but more effective.

\section{An Illustrative Case of Simulated Hysteria and Mental Debility.}

The patient was a young negro accused of murdering his wife, seen in consultation with Dr. Shute, the jail physician, on account of a suspicion that he was a case of dementia præcox. I was informed that some physicians believed him hysterical, and that others thought he was suffering from syphilis of the nervous system.

On examination, I found a well developed man who showed no abnormalities of motility. 
REFLEXES.

The knee-jerk was made very violently (the explanation of this will appear); but there was no corresponding excessive reaction on tapping the tendo-achilles, nor was there extension of the great toe when the sole was stroked. The abdominal, cremasteric and conjunctival and pupillary reflexes were present and equal.

\section{SENSIBILITY.}

His Suspiciousness.-He was very unwilling to close his eyes for my examination of the sensibility; and when touched by wool on the right side, opened them and jumped in alarm. He stated that he could not feel at all on the left side; but all his responses were made after much delay, and he was evidently suspicious and alarmed. The sense of attitudes was not lost; for though he pretended not to know in what position I had placed his left foot, he imitated that position when asked to do so. He declared that he could not feel the increase as I gradually augmented to 15 kilograms my pressure on the left shoulder. As he was unsupported and in the upright position, he must have been conscious, at least, of the muscles of the opposite side acting to maintain his attitude. Of course, even had the impulses from the muscles on the affected side been interrupted, as he pretended, the sound side would have detected the pressure; but he persistently declared that he felt nothing at all.

The diagnosis of simulation was clinched by the fact that though he pretended not to feel a pin-prick anywhere on the left side, yet when I distracted his attention by making him examine some pictures ${ }^{25}$ I had brought to elucidate his mental state, and jabbed him unexpectedly with a pin in the lower part of the left chest, he not only started violently, but he placed his hand over the spot, and first looked down and then at me. As I gave no sign, he slowly returned his eyes to the examination of the picture. The visual fields were not contracted.

As to his mental state, though it was apparently very dull, the stupidity he affected did not concord with the results of the tests I made. When I asked him how long he had been in jail he pretended with a vague stare not to know, eventually saying, "Twothree years" (he had only been a few weeks).

By adopting a matter-of-fact manner and ignoring his expecta- 
tions of meeting with a naif credulity to which he had evidently been accustomed, I succeeded in learning that he had been footman to a gentleman in the Department of Commerce and Labor, who lived in a hotel and who kept a white maid and a colored coachman who lived out. He did not admit, however, the remembrance of his name. His intelligence was thus of too low a grade even to pretend a tenable amnesia. I then showed him the pictures, in which at first he pretended not to recognize a tree; but later he saw the absurdity of his first statement that a man was holding in his hand a stick, when in reality it was a hose from which water was issuing; for he not only saw the absurdity when told, but detected the break in the hose. My experience shows that not every individual, even of good intelligence, detects this discrepancy. In another case, he recognized that a horse pulling a sled up hill was not properly hitched, the chain not being taut; this discrepancy is rarely detected by patients. He thus showed a power of perception utterly at variance with the stupidity he alleged to me and to previous observers. Some weeks later, he was said to have contracture of visual fields. On examination, he again alleged hemianæsthesia; but I again tripped him up on one occasion, although several methods failed, on account of his previous experiences. However, he ultimately confessed to feeling pinches on the back of his hand. He related various events to me quite clearly and accurately.

Being given the benefit of a doubt which should not have existed, he was sent to the asylum; and I am informed that now he shows no somatic symptoms, and merely the mental state of belonging to a low type of intelligence without any psychosis.

I should add that the hemianæsthesia presented the characters of the hysterical type, ${ }^{26}$ that is to say: (I) it was absolute; (2) affected all segments equally, and (3) reached the mid-line exactly. Whether its source was in medical suggestion or simple simulation could not be ascertained; for of course the patient did not confess; and the numerous medical examinations which had been made without the precautions upon which Babinski ${ }^{17}$ has insisted afford a strong presumption of suggestion of medical origin; for it is the commonest source of anæsthesia of this type. The exaggeration of the knee-jerks was a voluntary one, and can be easily simulated, as anyone can prove by trying it. This mode 
of reaction can be detected by an experienced observer. It probably was the result of the interest shown in it at the first examination.

THE GENESIS OF SIMULATION IN HYSTERIA.

The case was clearly then, one of simulation from desire to avoid punishment for the crime he had committed. The form in which the symptoms manifested themselves was determined by the faulty technique in previous medical examinations. The fault was similar to that stigmatized by Soury ${ }^{18}$ when he criticized Rainaldi's ${ }^{10}$ localization of cortical centers in conformity with the symptoms manifested when he tapped different points of the crania of patients during hypnotism: "The symptoms corresponded with the text-books which the different experimenters had read." What the observers had described was the result of their own suggestions.

And so it was in this case, both for the hemianæsthesia and the knee-jerk. Moreover, by his mental reaction, the patient did his best to conform to the dementia syndrome which his interlocutors had in mind. But when a precise and rigorous method of examination had been pursued without parti pris, a very different picture presented itself, that of deliberate simulation in an ignorant person of low intelligence.

Many alienists have stated that a simulator is of necessity abnormal. While in the strict sense this is true, yet in some cases it is only so on account of a faulty environment having determined anti-social reactions in a person in himself quite capable of normal social reactions had the environment been healthy. The trouble is sociological rather than medical.

On the other hand, simulation is often performed through imitation, which is a form of suggestion. The best example of this is the psychic contagia so frequently seen in hospitals among the attendants and patients when these are of inferior intellectual grade. The hysterical crises of Charcot's day were a striking example. Now-a-days, a case of appendicitis in a woman's college will bring twenty girls to the doctor complaining of symptoms which they imitate according to fancy. I need not here insist upon the psychology of imitation, upon which these phenomena depend. They are inextricably intermingled with those of suggestion. 
Again, consciousness is a matter of degree; and a person who imitates or is suggested into a symptom without knowing how or why may conveniently be called a hysteric: he is not clearly conscious of the process by which he believes. The simulator, on the other hand, imitates his symptom deliberately and with intent to deceive. The line is not easy to draw ; for each consciously or unconsciously grasps at every straw by the way in order to fortify and make to prevail his mental pose. Both states are favored by the same mental make-up. Its tendency is towards impressionability without complex co-ordination, and to facility of judgment without reflection. The state is commonest during the pubescence of young girls, and is conduced to by faulty education in conjunction with the tremendous demands for psychic readjustments at puberty.

The Diagnosis of Simulation.

NEUROLOGICAL SIGNS.

The difference between the deliberate simulator who wishes to gain an end and the real hysterical is that the latter cannot be tripped up in the way in which this patient was trapped. When by psychotherapy, a hysterical anæsthesia is made to disappear, the patient continues to feel for some time at least, $i$. e., until the suggestion which has caused the anæsthesia regains the ascendency. Our malingerer on the contrary showed that he felt only when he was surprised into doing so, and never expressly. A true hysterical is, as a rule, unsuspicious; for he is so dominated by his induced-idea, in which indeed he believes firmly, that he has no cause for alarm.

I do not intend to discuss our patient's simulation of dementia and amnesia. The means for unmasking this very common attempt are well known; they need not be insisted upon, as they are brought out, although shortly, in the history.

Simulators often pretend motor disability. If it is hemiplegia, the subject does not, as a rule, swing the leg as does a truly paralyzed man.

Again, when arising from a lying position, the simulator uses both haunches, which a man who has a completely paralyzed leg is unable to do. 
If the arm is alleged to be affected, one will always be able to detect different inequalities in the grasp as measured by the dynamometer at different times. This is most clearly shown when the simulator's attention is distracted while he squeezes the instrument.

If the arm is contractured, to and fro passive movements would generally reveal anomalous muscular contractions especially while the patient's attention is diverted from what one is doing.

A completely paraplegic man, even though he may sit propped in a chair, is incapable of moving himself onto another one: a simulator who does not know this can be unmasked.

In a simulated paralysis, there is no diminution or increase of tonus. This can be shown by the fact that there is no depression of the affected shoulder or falling of the hand or foot when at rest; and the examiner cannot overflex the forearm or hyperextend the knee.

The "hand-falling sign" of Ramist" is ascertained by gently maintaining the patient's hand and forearm in a vertical position while his elbow is rested upon a table, bed or the arm of a chair, and while distracting his attention, quietly letting go the hand. If there is an organic paralysis, the hand will fall; if not, it remains extended for a considerable period.

Contractures.-Severe hemiplegia with contracture is always accompanied by associated movements. There are no such movements in psychic or simulated paralyses. When an effort is made to move the paralyzed limb, the movements which occur on the other side of the body are always the same in the same case; and they correspond to the strongest normal movement of the limb. In the arm, it is flexion towards the mouth; in the lower limb, it is extension, accompanied by elevation of the heel. An important fact is that organic contracture is never complete, is most severe distally, and is usually in the antagonists of the strongest muscles.

The Walk.-In walking sideways, a paralyzed patient only drags the foot on the floor when walking towards the sound side; simulators usually will drag the foot along the floor in walking towards the side they believe unsound.

I need not insist upon the now well known dorsi-flexion of the toe which characterizes organic affections of the cortic-spinal 
path; nor need I discuss the combined flexion sign, which we also owe to Babinski; and I need only mention the sign described by Hoover, and its modification of Zenner, which depends upon the synergic downward pressure of one lower limb when a patient attempts to raise its fellow while both are extended upon the bed. They are all now elementary neurological tests.

Sensory Symptoms.-To detect the simulation of a hyperæsthetic area, the examiner may press at the same time with two fingers, one on the painful spot and the other close by, so as to cause both impressions to be felt as one. Pressure on the alleged hyperæsthetic area is then to be gradually ceased. A simulator will continue to complain of pain. Of course a really painful spot will cause a more rapid pulse when it is pressed upon, and may also produce homolateral dilatation of the pupil. But these signs are both inconstant and difficult to estimate even with the aid of the sphygnamomanometer, which may, however, show an alteration of the plateau and a dicrotism.

It is very difficult to unmask simulated deafness; but simulated blindness is often revealed by an affection of clumsiness in buttoning the coat, touching the fingers together, striking a match, etc. A really blind man is quite adroit in any of these manœuvres. A hysterical patient with contracted visual fields does not fall over objects placed to either side, a simulator does so. Hartridge's " modification of the Flees' box is very convenient in unmasking simulated amaurosis of the eye.

The patient who simulates aphonia will pretend that he cannot whistle, which a hysterical generally does quite freely.

The simulation of hysterical convulsions may be taken for epilepsy, which itself is well known to be often simulated. In the true epileptic fit, the pupils are, however, paralyzed or at least sluggish; and blood and urinary changes, chemical or physical, should render the diagnosis not difficult.

Flora has alleged that the muscles that are weakened in the course of a traumatic neurosis "nearly" failed to respond by tetanos to long faradic stimulation. His assertions have not been confirmed; and I have no experience of the test. The same may be said of Lombroso's allegation that the temperature is one degree lower on the diseased side.

In conclusion, I need only emphasize the importance of a knowl- 
edge of, and capacity to use at the bed side, neurological signs, which, in conjunction with clear conceptions of the natural history of nervous disease are the only means by which the physician can hope to diagnose the simulation of hysteria.

\section{REFERENCES.}

I. Author: The Trend of the Clinicians Concept of Hysteria. Boston Med. Jour., 1909, March 25.

2. - Le Definition de l'Hysterie. Rev. Neurol., I90I.

3. Discussion sur l'Hysterie. Soc. de Neurol. de Paris, 1907. Also see Author's Status of Hysteria, New York Med. Jour., 1909; Jan. 9.

4. Author: The Nature of Hysteria. International Clinics, Autumn, 1908. 5. Babinski: Ma Conception de l'Hysterie. Paris, 1906.

See also Trans. by Chaddock Interstate Med. Jour., 1908.

6. See Report in Revue Neurologique, 1907.

7. Author: The differential Diagnosis of Neurasthenia from Conditions for which it is Often Mistaken. Arod. of Diag., Jan., I908.

Also The Positive Diag. of Hysteria and Psychasthenia. New Orleans Med. Jour., May, Ig09, etc.

Also Genesis of Hysterical Symptoms and their Relation to Fears and Obsessions in Childhood. Med. Record, Aug. 6, 1910.

8. - Revue Neurologique, Dec., 1909; Jan., 1910.

9. Author: The Relative Value of the Affective and Intellectual Processes in Inducing Traumatic Neurosis. Jour. Abnor. Psychol., 1910.

See also an article in Med. Record, Oct. 9, 1909.

10. See Discussion sur l'Hysterie, Loc cit.

II. Janet employs this criterion in his works Automatisme Psychologique, 1889. Névroses et Idées Fixes, I897, and The Major Symptoms of Hysteria, 1908.

12. Freud: Explains Psychoneuroses as the result of the Intrusion of unpleasant ideas driven out of consciousness by the Patient. These act as foreign bodies, and attract other thoughts, as bacteria do leucocytes.

See Sammlung kleiner Schriften zur Neurosenlehre, 1906.

Also Selected papers on Hysteria. Trans. by Brill, New York, I909.

13. Freud: Applies this word to his method of cure by Psycho-analysis. It depends upon the principle that submerged ideas lose their unpleasantness and cease to cause distress as soon as they are freely expressed.

See also Jung. Zur der Psychologie oder Dementia Pracox, also Translated in Nervous and Mental Monographs, New York, I908.

See also Psychotherapeutics, $A$ Symposium, Jour. of Abnormal Psychol., July, 1909, for a clear and short account of the principles. 
14. Author: The Importance of Modifications of the Sensibility in the Diagnosis of Disease. Amer. Jour. Med. Sci., April, 1909.

15. Toulouse, Pieron et Vaschide: Examen des Sujets. Paris, Igor.

16. Déjérine: Sémiologie des Maladies du Systeme Nerveux. Traité de Med. de Bouchard-Brissaud, 1900.

17. - Le Démembrement de l'Hysterie, Semaine Med., Jan., I909.

18. - Un Cas d'Autosuggestion Scientifique, Revue de l'Hypnotisme, 1903.

19. - La Localizzazoni Cerebrali in un Caso d'Ipnotism. Foligno, I891, Vol. I.

20. - Une Nouvelle signe d'Hemiplegie Organique. Revue Neurologique, 1909, Nov. 30.

2I. — The Diaphragm Test for Binocular Vision. Brit. Med. Jour., Oct., 1909.

22. —— Clinica Moderna, XI, Nos. IO, II. 